\title{
Peertechz
}

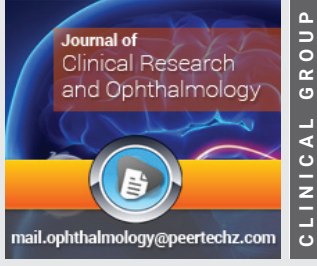

\section{Normal tension glaucoma: Prevalence, etiology and treatment}

\author{
George Ayoub ${ }^{1,2 *}$, Yanan Luo ${ }^{3}$ and Dominic Man-Kit Lam ${ }^{1}$ \\ ${ }^{1}$ World Eye Organization, 1209 Shui on Centre, 6 Harbour Road, Hong Kong \\ 2Department of Psychology, University of California, Santa Barbara, CA, 93106, USA \\ ${ }^{3}$ College of Chemistry, Central China Normal University, Wuhan, 430079 PRC, China
}

Received: 21 April, 2021

Accepted: 29 April, 2021

Published: 30 April, 2021

*Corresponding authors: Dr. George Ayoub, Department of Psychology, University of California, Santa Barbara, CA, 93106, USA, E-mail: ayoub@worldeye.org ORCID: https://orcid.org/0000-0002-0807-8983 https://www.peertechzpublications.com

\section{Check for updates}

\section{Abstract}

Normal tension glaucoma is the most common type of glaucoma among people of east Asian countries. While a significant minority of cases of normal tension glaucoma respond to drugs or surgical procedures that lower intra-ocular pressure, most cases continue to progress, resulting in a continuing loss of visual field and blindness. We here review the current state of knowledge of this debilitating disease, and evaluate a promising pilot study showing a potential route to evaluate normal tension glaucoma and to effectively treat it with a vitamin and mineral supplement.

\section{Introduction}

Glaucoma is a visual disorder that is increasing in prevalence. While most cases of glaucoma world-wide present with an increased pressure in the eye, the majority of cases of open-angle glaucoma in China, Japan and Korea have normal intraocular pressure (IOP) and are called normal tension glaucoma (NTG). Clinical evaluation indicates that abnormal retinal blood flow is a feature of any glaucoma but in particular of NTG, a condition with few treatment options, and one that results in glaucomatous optic neuropathy (GON) and diminished visual field.

Recent evidence has identified that while IOP is normal in NTG, measurement of retinal venous pressure (RVP) reveals often elevated levels. Current treatment for NTG is limited to reduction in IOP, which is marginally effective. RVP increases are often associated with disturbed microcirculation, due to limited autoregulation and altered endothelial cells related e.g. to Flammer syndrome. A reduction of GON from NTG in response to vitamin supplementation to restore normal RVP, as detailed in this review, will provide a powerful tool to curtail progression of NTG. Additionally, using RVP measurement as a biomarker for NTG provides an early diagnostic for this debilitating disorder.
A three month pilot study with glaucoma patients that directly tested this hypothesis has proven effective in identifying NTG and presumed NTG by the presence of elevated RVP. Treatment of patients with Ocufolin forte was effective in reducing RVP as well as elevated homocysteine levels, a biomarker for deficiencies. Ocufolin contains micronutrients and is well tolerated, with no reported adverse implications. We suggest RVP screening of those at risk for NTG and treatment of elevated RVP with Ocufolin forte as a viable diagnosis and treatment for this common type of glaucoma.

\section{Epidemiology}

Globally, glaucoma impacts over 70 million people with one in ten bilaterally blind, making it the leading cause of irreversible blindness. Glaucoma is often asymptomatic prior to vision reduction, so those afflicted is likely much greater than reported numbers [1]. Worldwide, all types of glaucoma account for $6.5 \%$ of blindness, and the prevalence of glaucoma of all types is $3.5 \%$ for people over 40 years [2]. Tham, et al. [3] projected an increase of $50 \%$ of all types of glaucoma in the next two decades.

The global prevalence of all types of glaucoma is detailed by Chen et al [4], Tham, et al. [3] and Kim, et al. [5]. Within Asian populations, normal tension glaucoma (NTG) comprises $70 \%$ 
of primary open angle glaucoma (POAG), with values 75-90\% in China, Singapore, Japan and Korea, and 50-70\% in India and Nepal [5]. Diagnosis of NTG is determined from the presence of POAG signs such as damage to the optic nerve head in the presence of normal Intraocular Pressure (IOP). The standard treatment of NTG is to lower IOP, control systemic risk factors and improve ocular perfusion.

High tension glaucoma predominates in people with origins in Africa and Europe, while NTG predominates in people with origins in east Asia. In the Wang, et al. [6] consensus report on NTG in China, which draws from the major medical centers in China, they identified NTG afflicting $1 \%$ of the Chinese population, and that NTG comprises $70 \%$ of POAG cases. They report that in healthy populations, the average IOP is 17 for white people and 15 for Chinese, while POAG averaged 22 [6]. They found that patients meeting the characteristics of Flammer Syndrome (FS) have a lower intracranial pressure, leading to an increased gradient at the lamina cribosa, and a resultant decrease in perfusion of the optic nerve. Wang, et al. [6] provide guidance for treatment of NTG based on patient specifics.

Flammer syndrome, which is often associated with NTG, describes a phenotype of people having a predisposition for an altered vascular reaction to stimuli such as cold, emotional stress or high altitude. Common symptoms are: cold extremities, low blood pressure, prolonged sleep onset time, reduced feeling of thirst, increased sensitivity to odor, pain vibration and certain drugs. FS subjects are often ambitious, successful, perfectionists and sometimes brooding. Frequent signs are: altered gene expression, prolonged blood flow cessation in nailfold capillaroscopy after cold provocation, reduced autoregulation of ocular blood flow, and reduced retinal vasodilation after stimulation with flickering light. Retinal venous pressure is on average higher and retinal astrocytes are more often activated. FS occurs more often in females than in males, in thin than in obese subjects, in young than in old people, in graduates than in blue collar workers, in subjects with indoor than outdoor jobs [7]. Associated diseases are: normal tension glaucoma, occlusion of ocular vessels, retinitis pigmentosa, multiple sclerosis, tinnitus or even sudden hearing loss.

\section{Etiology}

NTG, alternately termed low tension glaucoma or normal pressure glaucoma, manifests with optic disc flame hemorrhages and cupping, while IOP remains under $21 \mathrm{mmHg}$ $[8,9]$. While NTG is generally considered to be similar to POAG in the outcomes, its etiology is different, and the mechanism of damage is different from POAG with high IOP [10].

Current thinking on NTG is that damage to the retina may be due to a lack of perfusion, with reports of disrupted ocular blood flow (OBF) [11] possibly due to an increase in retinal venous pressure (RVP) causing damage to the axons of the retinal ganglion cells that comprise the optic nerve [1].

Trivli et al [9] reviewed NTG pathogenesis, and developed a model (Figure 1) showing that an increase in RVP causes a decrease in OBF, which impacts the Retinal Ganglion Cells (RGC), resulting in a change in the Optic Nerve Head (ONH). Wareham and Calkins [12] provided an excellent review detailing the impact of glaucoma on retinal vasculature, including diagrammatic clarity and the role of hormones on the endothelial cell making up the retinal arteries. Additionally, Wang, et al, [13] explained that a pressure mismatch in POAG was created by either high IOP or low cerebrospinal fluid (CSF) pressure, resulting in a pressure gradient at the lamina cribosa that leads to Glaucomatous Optic Neuropathy (GON).

The work of Fan et al [14,15] showed that NTG has a disturbed OBF as measured with imaging techniques, and NTG is comorbid with systemic disorders, including migraine, hypotension, Alzheimer's disease and Flammer Syndrome $[7,16]$. Fan, et al. [15] suggest that NTG may not be glaucoma, but a group of disorders with GON. This has implications for what may be best practice in treatment.

Ocular blood flow (OBF) is on average less in glaucoma patients than in healthy controls. This reduction is more pronounced in normal-tension than in high-tension glaucoma, and it is more distinct in cases with progressing damage as compared to those with stable disease. OBF reduction has two effects on GON. The primary effect is a fluctuating supply of oxygen and micronutrients to the organs, leading to tissue damage. The fact that hypoxia-related factors are upregulated in eyes of glaucoma patients indicates oxygen depletion. It is, however, not constant hypoxia, but rather the fluctuation of the oxygen and micronutrient supply that leads to tissue damage, likely due to oxidative and nitrosative stress. Low perfusion pressure and disturbed autoregulation are major causes of the reduced blood supply causing oxygen and micronutrient variation, and both systemic hypotension and disturbed autoregulation are often consequences of the primary vascular dysregulation syndrome (PVD) [17,18]. The observed splinter hemorrhages in these patients are a consequence of a local breakdown of the blood-brain or blood-retinal barrier. The

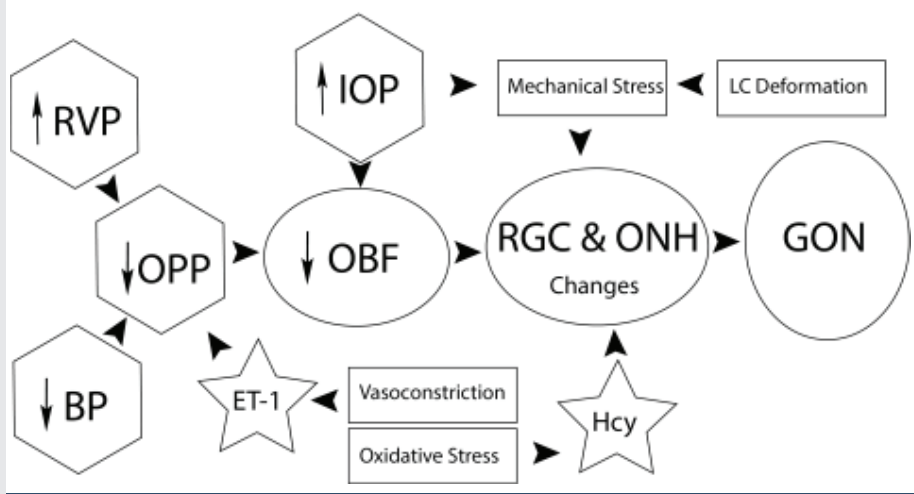

Figure 1: Schematic of the factors contributing to glaucomatous optic neuropathy $(\mathrm{GON})$ seen at the optic nerve head $(\mathrm{ONH})$. An increase in retinal venous pressure (RVP) decreases ocular perfusion pressure (OPP), which lowers ocular blood flow (OBF), exerting changes in the retinal ganglion cells (RGC) and $\mathrm{ONH}$. The common path that disturbs the $\mathrm{ONH}$ is increase in intraocular pressure (IOP). Additional paths to GON include deformation of the lamina cribosa (LC), mechanical or oxidative stress which increases homocysteine (Hcy), low blood pressure (BP), and vasoconstriction leading to an increase in the hormone endothelin-1 (ET-1). Effects are in ovals, pressures in hexagons, biomarkers in stars, and stresses in rectangles. Adapted from Trivli [9].

Citation: Ayoub G, Luo Y, Lam DMK (2021) Normal tension glaucoma: Prevalence, etiology and treatment. J Clin Res Ophthalmol 8(1): 023-028. 
often associated vein occlusions can be a consequence of local vein dysregulation [19].

Gugleta [20] described the significance of endothelin-1 (ET-1) in glaucoma. Endothelin-1 is vasoconstrictive and is a ubiquitous molecule that occurs in nearly all tissues. Its primary physiological function is regulation of blood vessel diameter and thus the regulation of blood supply in tissues. It is secreted locally and exerts its effects locally. Endothelin-1 is involved in the regulation of blood flow in the retina and the optic nerve [12].

Flammer and Konieczka [16] evaluated the role of endothelin on retinal venous pressure (RVP). In healthy subjects RVP is usually equal to or slightly above intraocular pressure (IOP), while RVP is often significantly increased in patients with eye or systemic disease.

This indicates endothelin-1 is a useful biomarker for RVP, with another important biomarker being homocysteine.

Homocysteine levels and the frequency of heterozygous methylenetetrahydrofolate reductase (MTHFR) C677T mutation are increased in open-angle glaucoma. Since homocysteine can induce vascular injury, alterations in extracellular matrix remodeling, and neuronal cell death, these findings may have important implications for understanding glaucomatous optic neuropathy [21].

In the comprehensive review of homocysteine as a biomarker by Smith and Refsum [22], they find 100 diseases or conditions that are associated with raised concentrations of plasma homocysteine. The commonest associations are with cardiovascular diseases and diseases of the central nervous system, but a large number of developmental and age-related conditions are also associated. Few disease biomarkers have so many associations. The clinical importance of homocysteine as a biomarker becomes apparent if lowering plasma homocysteine by B vitamin treatment can reduce disease. Smith and Refsum [22] reported five diseases that are diminished by lowering total homocysteine: neural tube defects, impaired childhood cognition, macular degeneration, primary stroke, and cognitive impairment in the elderly. They concluded that plasma homocysteine levels in adults of $10 \mu \mathrm{mol} / \mathrm{L}$ or less are probably safe, but that values of $11 \mu \mathrm{mol} / \mathrm{L}$ or above may justify intervention. Homocysteine is more than a disease biomarker: it may be a useful guide for the prevention of disease [22,23].

The data in Schmidl [24] showed that a three-month intake of a dietary supplement containing L-methylfolate can significantly reduce blood homocysteine levels in patients with diabetes. This is of importance because higher plasma levels of homocysteine are linked with an increased risk of vascular associated systemic diseases and eye diseases. The review of such nutritional therapies for treatment of diabetic retinopathy by Shi et al [25] gives the additional explanation of the utility of each component in the dietary supplement. Whether systemic L-methylfolate supplementation affects retinal perfusion must be studied in a larger population, but the utility of a single vitamin/mineral supplement to address nutritional deficiencies in retinal vasculature would be a logical extension of treatments supported by the Age-Related Eye Disease Studies (AREDS) [25].

Homocysteine (Hcy) and endothelin-1 are useful biomarkers for elevated retinal venous pressure. As seen in Devogelaere [26] Hcy is elevated in NTG and other types of glaucoma. Efficient reduction of Hcy with vitamin supplementation was already shown by Schmidl [24].

Retinal venous pressure (RVP) may be measured noninvasively by ophthalmodynamometry $[27,28]$. While RVP is equal to or slightly above IOP in healthy people, it is often increased in patients with eye or systemic diseases. Beyond mechanical obstruction, the main cause of such elevation is a local dysregulation of a retinal vein, typically a constriction induced by endothelin-1 (ET-1, Figure 1). Local increase of ET-1 can be due to a higher blood level, as ET-1 can diffuse from the fenestrated capillaries of the choroid into the optic nerve head $(\mathrm{ONH})$, bypassing the blood retinal barrier. A local increase can also result from increased local production either by a diseased retinal artery or retinal tissue. Generally, the main factors increasing ET-1 are inflammation and hypoxia. RVP is known to be increased in patients with glaucoma, retinal vein occlusion, diabetic retinopathy, high mountain disease, and primary vascular dysregulation (PVD). PVD is the major vascular component of Flammer Syndrome (FS). The increase in RVP decreases perfusion pressure, which increases the risk of hypoxia and ischemia. An increase of RVP also raises transmural pressure, which in turn raises the risk for retinal edema. In patients with retinal vein occlusion, elevated RVP may be both a consequence and a potential cause of the occlusion, causing a vicious circle. Narrowed retinal arteries and dilated retinal veins are known risk indicators for future cardiovascular events. As the major cause for retinal venous dilation is increased RVP, RVP may be an important marker.

Stodtmeister [29] recently documented a means to measure RVP with a contact lens dynamometer (Imedos, Jena, Germany). This device entails monitoring the retinal vein for pulsation while a pressure is applied to the sclera.

Until recently, the pressure in the intraocular veins was assumed to be equal to the IOP. According to Stodtmeister [30], the pressure in the central retinal vein may be considerably higher than the intraocular pressure. Therefore, the pressure in the retinal veins in the prelaminar layer of the optic nerve head is likely also higher than the IOP. In this case the perfusion pressure (arterial pressure minus central retinal venous pressure) is reduced (schematized in Figure 1). Since RVP is higher in glaucoma patients than in healthy subjects and in patients with unequal excavations, RVP is higher in the eyes with larger excavation, RVP is a considerable risk factor for the progression of glaucomatous damage. Such elevated RVP may be the reason IOP-lowering therapy is ineffective in eyes in which the pressure of the central retinal vein is higher than the intraocular pressure, a condition that may apply to about 40$50 \%$ of glaucoma patients $[29,30]$.

Alternatively, angiography of the retinal vasculature at the optic nerve head could provide a viable assessment for 
ocular blood flow. Optical coherence tomography angiography (OCTA), a dye-free, non-invasive imaging assessment, has recently been deployed to assess glaucomatous damage [31] They showed that glaucomatous eyes had a reduced blood flow and vessel density in the optic nerve head compared to control eyes. Additionally, Wang, et al. [32] showed that OCTA measurements correlate with visual field measurements, indicating that OCTA provides a direct route to assessing retinal perfusion. Thus, measurement of RVP and use of OCTA look to be valuable tools in assessing retinal health in glaucoma.

Of course, retinal venous pressure can also be increased in a clinically healthy eye. But nevertheless, it can be a strong sign of a systemic disorder, such as an autoimmune disease [33].

The ocular cause of an increase of RVP may either be a mechanical compression or a functional constriction of the vein at the exit of the eye. The consequences are decreased perfusion pressure, which increases the risk for hypoxia. Increased RVP also increases transmural pressure and thereby a risk for retinal edema.

Elevated RVP and elevated CSF pressure may have a single cause or one may be influenced by the other. Morgan [34] estimated the RVP effect by measuring the retinal vein ophthalmodynamometric force, and found that it, and not IOP, correlated with optic disc excavation. Morgan, et al. [35] noted that high myopia patients have a thin lamina cribosa, that this is exacerbated in myopic patients with glaucoma, and that a thinner lamina cribosa magnifies the pressure gradient effect by two to four times. This magnified effect may explain the more rapid progression of glaucoma in myopic patients including those having lower IOP.

In Fang, et al. [36], one frequent sign of NTG is an increase of the retinal venous pressure (RVP). The effect of FS on RVP was examined, measuring RVP in eyes of POAG patients and healthy subjects with and without FS. Results showed that RVP was higher in subjects with FS, particularly in FS subjects with glaucoma.

Pillunat, et al. [37] evaluated patients with IOP-controlled open angle glaucoma, examining those with early, moderate and advanced disease stages and compared these to a healthy control group. In more advanced cases of glaucoma, RVP was higher than expected.

Sung [38] found progression in visual field loss in NTG was related to an unstable ocular perfusion pressure (which is proportional to RVP if IOP is static) by measuring IOP over a 24 hour period. They found that visual field defects in NTG are more central than in patients with high IOP.

\section{Treatment}

Currently, the main goal of glaucoma treatment is the slowing of disease progression with the goal of preserving quality of life. The only tool to accomplish this has been reduction of IOP, with several multicenter trials providing evidence that reducing IOP slows the disease progression [1].
Thus, the recommended treatment for POAG, including NTG, is to decrease IOP. Glaucoma treatment uses two treatment strategies to reduce IOP: medication (topical or systemic) and surgical shunts [39]. Additionally, minimally invasive glaucoma surgery (MIGS) as well as cataract surgery in NTG patients [40] have shown promise in slowing disease progression. While IOP reduction is less effective for NTG, it is the only treatment available to date, so the current best practice is to lower IOP in NTG, with the American Academy of Ophthalmology advising to lower IOP to 8-12 $\mathrm{mmHg}$, and to exercise caution in using beta blockers due to the comorbidity of systemic nocturnal hypotension among NTG patients [41].

Decreasing IOP is minimally effective at preserving vision, but given it is the only option, it is the current standard of care. The evidence reported above that NTG presents with vascular deficiencies gives hope that improving ocular perfusion may be a potential treatment for NTG, as Fan, et al. [15] implies and Chen, et al. [4] postulate. Similarly, the controlled study showing an association between NTG and Flammer syndrome [42] points to a vascular origin of NTG that may be related to elevation of endothelin-1 [16], who report measuring Flammer syndrome in the eye by monitoring RVP.

A three month pilot study that directly tested this hypothesis has proven effective in identifying NTG and presumed NTG by the presence of elevated RVP [26]. Patients with elevated homocysteine levels were included in the study. Treatment of patients with Ocufolin ${ }^{\circledR}$ forte, (Aprofol, Switzerland) a vitamin cocktail that reduces FS damage, was effective in lowering homocysteine levels and reducing RVP. The reported values in the course of their 3 month trial are reproduced in Figure 2, and showed that RVP was reduced from 34.5 to $23.9 \mathrm{~mm} \mathrm{Hg}$, and homocysteine levels were reduced from 16.4 to $12.7 \mu \mathrm{mol}$. The Devogelaere, et al. [26] pilot study followed 23 patients (mean age $70 \mathrm{y}$ ) for three months with daily Ocufolin forte. 16 patients had confirmed glaucoma, and 3 were suspected glaucoma cases. NTG cases were 7 of the 16 and 1 of the 3. RVP was calculated from Ocular Dynamic Force (ODF) and IOP, using the formula RVP = ODF + IOP.

While IOP dropped from 12.1 before the trial to 11.5 at the conclusion of the trial, the decrease in RVP was striking. The authors reported Ocufolin forte was well tolerated by the patients and no side effects were observed. The findings of Devogelaere, et al. [26] are included below this report.

Their results suggest that RVP screening of those at risk for NTG is a viable evaluative method for this second most common type of glaucoma. Further, they suggest that addressing elevated RVP with Ocufolin is a valid approach for NTG treatment.

Work by the Flammer team has previously shown that in diabetic retinopathy there is an increase in retinal venous pressure (RVP) which is related to retinal endothelial cell damages [16]. A vitamin cocktail containing L-methylfolate Ocufolin ${ }^{\circledR}$ forte, (Aprofol AG, Switzerland) lowered IOP and Hcy in a three month trial with diabetic patients [24]. 
$\operatorname{RVP}(\mathrm{mmHg})$

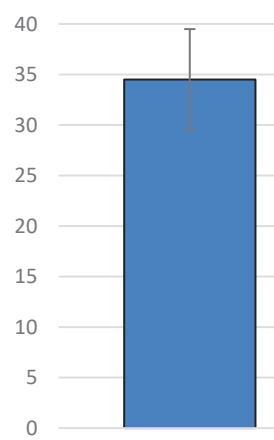

pre

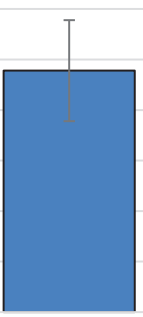

post
Homocysteine ( $\mu \mathrm{mol})$

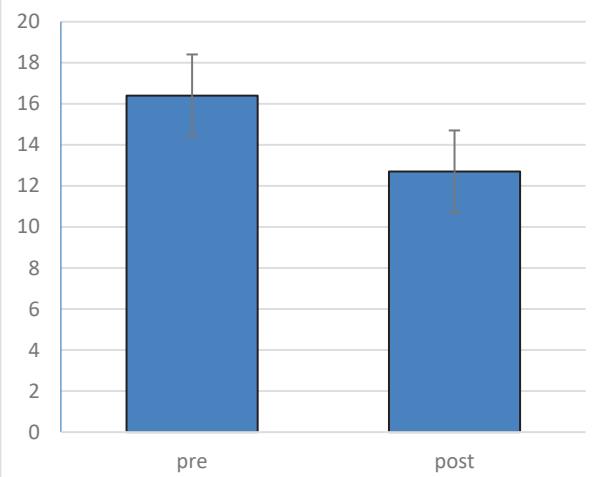

Figure 2: Devogelaere [26] (2021) found in their trial of patients with elevated homocysteine levels, that a daily capsule of a vitamin/mineral supplement (Ocufolin Forte, Aprofol, Switzerland) used in correcting the arterial damage seen in some cases of Flammer Syndrome (FS), was effective in reducing homocysteine levels (the precondition for inclusion in the study), and reducing retinal venous pressure (RVP), in the course of the 12 week study. Most subjects in this study had glaucoma, with approximately half having normal tension glaucoma (NTG). Elevated homocysteine appears to be a useful biomarker for increased RVP, which may be important in treating glaucoma that is not responsive to IOP reduction.

Given the safety of this treatment, and the prevalence of currently untreatable NTG, we suggest consideration of the use of Ocufolin forte for diagnosed NTG cases with elevated RVP, in conjunction with regular monitoring of RVP and clinical evaluation of GON.

\section{Conclusion}

Given the link of RVP with NTG and other eye conditions, and the potential to treat RVP with a mixture of micronutrients having no known adverse effects, we suggest the use of RVP measurement or OCTA screening to assess for NTG in glaucomatous patients and to screen for early NTG in those with risk factors for local or systemic micronutrient deficiencies caused by various reasons. While RVP measurement may feel less comfortable for elderly patients than IOP measurement, it will permit the skilled ophthalmologist to identify and track NTG and to monitor treatment with the vitamin cocktail. We believe screening for FS characteristics will reduce RVP measurements to those at risk for NTG, and will allow the medical community to directly address this significant cause of blindness in a manner to reduce its impact. We suggest that glaucoma patients who are progressing despite adequate IOP control may benefit from RVP and homocysteine evaluation, in addition to the potential benefit of MIGS or early cataract surgery.

While the measurement of RVP is non-trivial, we believe it will be a useful tool for early diagnosis and for monitoring treatment of NTG, and provide a significant advance in treatment of this major cause of blindness.

\section{References}

1. Weinreb RN, Aung T, Medeiros FA (2014) The pathophysiology and treatment of glaucoma: a review. JAMA 311: 1901-1911. Link: https://bit.ly/3eFGZiL

2. Jonas JB, Aung T, Bourne RR, Bron AM, Ritch R, et al. (2017) Glaucoma Lance 390: 2183-2193. Link: https://bit.ly/3nuvNcK

3. Tham YC, Li X, Wong TY, Quigley HA, Aung T, et al. (2014) Global Prevalence of Glaucoma and Projections of Glaucoma Burden through 2040: A Systematic Review and Meta-Analysis. Ophthalmology 121: 2081-2090. Link: ttps://bit.ly/2QyJE5Y

4. Chen MJ (2020) Normal tension glaucoma in Asia: Epidemiology, pathogenesis, diagnosis, and management. Taiwan J Ophthalmol 10: 250254. Link: https://bit.ly/3vmiz4u

5. Kim KE, Park KH (2016) Update on the Prevalence, Etiology, Diagnosis, and Monitoring of Normal-Tension Glaucoma. Asia Pac J Ophthalmol (Phila) 5 23-31. Link: https://bit.ly/3t6o5Xs

6. Wang NL (2019) The expert consensus on the diagnosis and treatment of normal tension glaucoma in China (2019 Edition). Chin J Ophthalmol 55: 329332.

7. Konieczka K, Ritch R, Traverso CE, Kim DM, Kook MS, et al. (2014) Flammer syndrome. EPMA J 5: 11. Link: https://bit.ly/2R6hX4m

8. Karmel M (2021) Normal-Tension Glaucoma, Part One: Diagnosis. EyeNet Magazine.

9. Trivli A, Koliarakis I, Terzidou C, Goulielmos GN, Siganos CS, et al. (2019) Normal-tension glaucoma: Pathogenesis and genetics. Exp Ther Med 17: 563574. Link: https://bit.ly/32Vs3Yt

10. Lee JWY, Chan PP, Zhang X, Chen LJ, Jonas JB (2019) Latest Developments in Normal-Pressure Glaucoma: Diagnosis, Epidemiology, Genetics, Etiology, Causes and Mechanisms to Management. Asia Pac J Ophthalmol (Phila) 8: 457-468. Link: https://bit.ly/3voRQV5

11. Mozaffarieh M, Flammer $\mathrm{J}$ (2013) New insights in the pathogenesis and treatment of normal tension glaucoma. Curr Opin Pharmacol 13: 43-49. Link: https://bit.ly/3e3mL3a

12. Wareham LK, Calkins DJ (2020) The Neurovascular Unit in Glaucomatous Neurodegeneration. Front Cell Dev Biol 8: 452. Link: https://bit.ly/3e1rLFR

13. Wang N, Xie X, Yang D, Xian J, Li Y, et al. (2012) Orbital cerebrospinal fluid space in glaucoma: the Beijing intracranial and intraocular pressure (iCOP) study. Ophthalmology 119: 2065-2073 e2061. Link: https://bit.ly/2PwBFph

14. Fan $N$, Wang $P$, Tang L, Liu X (2015) Ocular Blood Flow and Normal Tension Glaucoma. Biomed Res Int 2015: 308505-308505. Link: https://bit.ly/3aMwl3h

15. Fan N, Tan J, Liu X (2019) Is "normal tension glaucoma" glaucoma? Med Hypotheses 133: 109405. Link: https://bit.ly/32YZnha

Citation: Ayoub G, Luo Y, Lam DMK (2021) Normal tension glaucoma: Prevalence, etiology and treatment. J Clin Res Ophthalmol 8(1): 023-028. 
16. Flammer J, Konieczka K (2015) Retinal venous pressure: the role of endothelin. EPMA J 6: 21. Link: https://bit.ly/2R6ivqW

17. Flammer J, Konieczka K, Bruno RM, Virdis A, Flammer AJ, et al. (2013) The eye and the heart. Eur Heart J 34: 1270-1278. Link: https://bit.ly/3gMLieX

18. Flammer J, Konieczka K, Flammer AJ (2013) The primary vascular dysregulation syndrome: implications for eye diseases. EPMA J 4: 14-14. Link: https://bit.ly/3vxpoAv

19. Flammer J, Konieczka K, Flammer AJ (2011) The Role of Ocular Blood Flow in the Pathogenesis of Glaucomatous Damage. US Ophthalmic Rev 4: 84-87. Link: https://bit.ly/3e6sANH

20. Gugleta K (2018) Significance of Endothelin-1 in Glaucoma - a Short Overview Klin Monbl Augenheilkd 235: 140-145. Link: https://bit.ly/2QEmf2V

21. Bleich S, Jünemann A, von Ahsen N, Lausen B, Ritter K, et al. (2002) Homocysteine and risk of open-angle glaucoma. J Neural Transm (Vienna) 109: 1499-1504. Link: https://bit.ly/3xw7FLx

22. Smith AD, Refsum H (2021) Homocysteine - from disease biomarker to disease prevention. J Intern Med. Link: https://bit.ly/3gMF66x

23. George AK, Majumder A, Ice H, Homme RP, Eyob W, et al. (2020) Genes and genetics in hyperhomocysteinemia and the "1-carbon metabolism": implications for retinal structure and eye functions. Can J Physiol Pharmacol 98: 51-60. Link: https://bit.ly/2S7P345

24. Schmidl D, Howorka K, Szegedi S, Stjepanek K, Puchner S, et al. (2020) A pilot study to assess the effect of a three-month vitamin supplementation containing L-methylfolate on systemic homocysteine plasma concentrations and retinal blood flow in patients with diabetes. Mol Vision 26: 326-333. Link: https://bit.ly/2QF8aCm

25. Shi C, Wang P, Airen S, Brown C, Liu Z, et al. (2020) Nutritional and medical food therapies for diabetic retinopathy. Eye Vis 7: 33. Link: https://bit.ly/3eLanEu

26. Devogelaere T (2021). Link: https://bit.ly/3aLR10s

27. Mozaffarieh M, Bärtschi M, Henrich PB, Schoetzau A, Flammer J (2014) Retinal venous pressure in the non-affected eye of patients with retinal vein occlusions. Graefes Arch Clin Exp Ophthalmol 252: 1569-1571. Link: https://bit.ly/3aJOVQH

28. Mustur D, Vahedian Z, Bovet J, Mozaffarieh M (2017) Retinal venous pressure measurements in patients with Flammer syndrome and metabolic syndrome. EPMA J 8: 339-344. Link: https://bit.ly/3e3izR8

29. Stodtmeister R, Koch W, Georgii S, Pillunat KR, Spörl E, et al. (2021) The Distribution of Retinal Venous Pressure and Intraocular Pressure Differs Significantly in Patients with Primary Open-Angle Glaucoma. Klin Monbl Augenheilkd. Link: https://bit.ly/3xvlxo5

30. Stodtmeister R (2008) Zentralvenenpuls, Zentralvenendruck und Glaukomschaden. Klin Monbl Augenheilkd 225: 632-636. Link: https://bit.ly/3aN5bPg

31. Rao HL, Pradhan ZS, Suh MH, Moghimi S, Mansouri K, et al. (2020) Optical Coherence Tomography Angiography in Glaucoma. J Glaucoma 29: 312-321. Link: https://bit.ly/3ntf490

32. Wang $X$, Jiang C, Ko T, Kong X, Yu X, et al. (2015) Correlation between optic disc perfusion and glaucomatous severity in patients with open-angle glaucoma: an optical coherence tomography angiography study. Graefes Arch Clin Exp Ophthalmol 253: 1557-1564. Link: https://bit.ly/3vtCdM1

33. Wakefield D, Wildner G (2020) Is glaucoma an autoimmune disease? Clin Transl Immunology 9: e1180-e1180. Link: https://bit.ly/32VNCrR
34. Morgan WH, Hazelton ML, Balaratnasingamm C, Chan $\mathrm{H}$, House $\mathrm{PH}$, et al. (2009) The association between retinal vein ophthalmodynamometric force change and optic disc excavation. Br J Ophthalmol 93: 594-596. Link: https://bit.ly/3aNUxYx

35. Morgan WH, Balaratnasingam C, Lind CRP, Colley S, Kang MH, et al. (2016) Cerebrospinal fluid pressure and the eye. $\mathrm{Br} \mathrm{J}$ Ophthalmol 100: 71-77. Link: https://bit.ly/3eE1cp7

36. Fang L, Baertschi M, Mozaffarieh M (2014) The effect of flammersyndrome on retinal venous pressure. BMC Ophthalmol 14: 121. Link: https://bit.ly/3xw8m7B

37. Pillunat KR, Ventzke S, Spoerl E, Furashova O, Stodtmeister R, et al. (2014) Central retinal venous pulsation pressure in different stages of primary openangle glaucoma. Br J Ophthalmol 98: 1374-1378. Link: https://bit.ly/3aQiP45

38. Sung KR, Cho JW, Lee S, Yun SC, Choi J, et al. (2011) Characteristics of Visual Field Progression in Medically Treated Normal-Tension Glaucoma Patients with Unstable Ocular Perfusion Pressure. Invest Ophthalmol Visual Sci 52 737-743. Link: https://bit.ly/3gMFQZn

39. Killer HE, Pircher A (2020) What is the optimal glaucoma treatment: reducing aqueous humour production or facilitating its outflow? Eye 34: 1719-1721. Link: https://bit.ly/3e23wXP

40. Minkus CL, Hunt S, Anchala A, Chaku M (2018) Cataract Surgery in Low Tension Glaucoma Patients. Invest Ophthalmol Visual Sci 59: 2708-2708. Link: https://bit.ly/2PyBQAD

41. Karmel M (2021) Normal-Tension Glaucoma, Part Two: Treatment. EyeNet Magazine. Link: https://bit.ly/2RcwF9J

42. Konieczka K, Choi HJ, Koch S, Fankhauser F, Schoetzau A, et al. (2017) Relationship between normal tension glaucoma and Flammer syndrome. EPMA J 8: 111-117. Link: https://bit.ly/3eE1r3v
Discover a bigger Impact and Visibility of your article publication with

Peertechz Publications

\section{Highlights}

* Signatory publisher of ORCID

* Signatory Publisher of DORA (San Francisco Declaration on Research Assessment)

- Articles archived in worlds' renowned service providers such as Portico, CNKI, AGRIS, TDNet, Base (Bielefeld University Library), CrossRef, Scilit, J-Gate etc.

* Journals indexed in ICMJE, SHERPA/ROMEO, Google Scholar etc.

* OAI-PMH (Open Archives Initiative Protocol for Metadata Harvesting)

* Dedicated Editorial Board for every journa

* Accurate and rapid peer-review process

* Increased citations of published articles through promotions

* Reduced timeline for article publication

Submit your articles and experience a new surge in publication services (https://www.peertechz.com/submission).

Peertechz journals wishes everlasting success in your every endeavours.

Copyright: @ 2021 Ayoub G, et al. This is an open-access article distributed under the terms of the Creative Commons Attribution License, which permits unrestricted use distribution, and reproduction in any medium, provided the original author and source are credited.

Citation: Ayoub G, Luo Y, Lam DMK (2021) Normal tension glaucoma: Prevalence, etiology and treatment. J Clin Res Ophthalmol 8(1): 023-028. DOI: https://dx.doi.org/10.17352/2455-1414.000088 